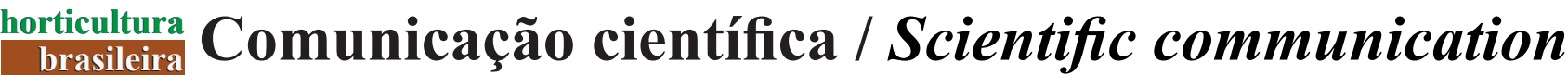

CARMONA PAO; PEIXOTO JR; AMARO GB; MENDONÇA MA. 2015. Divergência genética entre acessos de batata-doce utilizando descritores morfoagronômicos das raízes. Horticultura Brasileira 33: 241-250. DOI - http://dx.doi.org/10.1590/S0102-053620150000200017

\section{Divergência genética entre acessos de batata-doce utilizando descritores morfoagronômicos das raízes}

\author{
Paula AO Carmona ${ }^{1}$; José R Peixoto ${ }^{1}$; Geovani B Amaro ${ }^{2}$; Marcio A Mendonça ${ }^{1}$ \\ 1UnB-FAMV, Campus Universitário Darcy Ribeiro, Asa Norte, 70910-970 Brasília-DF; osorio.carmona@gmail.com; peixoto@unb.br; \\ marcioamen@gmail.com; ${ }^{2}$ Embrapa Hortaliças, C. Postal 218,70351-970 Brasília-DF; geovani.amaro@embrapa.br
}

\section{RESUMO}

O conhecimento da divergência genética disponível em um conjunto de genótipos é de grande importância em programas de melhoramento, por evitar recombinações gênicas semelhantes, com consequente aumento da expressão heterótica em híbridos e de ganhos genéticos em gerações segregantes. Objetivou-se caracterizar morfoagronômicamente 23 genótipos de batata-doce do banco ativo de germoplasma mantido na Embrapa Hortaliças; utilizar estas características para avaliar a variabilidade genética entre os materiais pela aplicação dos métodos de Análise por Agrupamento Hierárquico (AAH) e Análise por Componentes Principais (PCA) e estimar parâmetros populacionais. O experimento foi conduzido na Fazenda Água Limpa da UnB, em Brasília-DF. Os materiais foram cultivados em condições de campo no delineamento em blocos ao acaso com quatro repetições. Foram avaliados 8 caracteres das raízes. Os coeficientes de variação genética $\left(\mathrm{CV}_{\mathrm{g}}\right)$ e ambiental $\left(\mathrm{CV}_{\mathrm{e}}\right)$, a herdabilidade no sentido amplo $\left(\mathrm{h}_{\mathrm{a}}^{2}\right)$ e a razão $\mathrm{CV} / \mathrm{CV}_{\mathrm{e}}$ indicaram uma situação favorável para a seleção das características produtividade comercial, produtividade total, diâmetro e comprimento das raízes. Constatou-se que a maioria dos materiais genéticos avaliados é similar com relação aos descritores morfoagronômicos utilizados. Contudo, os cruzamentos entre genitores dissimilares como o clone CNPH 69, o qual destacou-se por sua alta produtividade comercial e total; o clone CNPH 80, que exibiu bom formato e moderada resistência aos insetos de solo e o clone CNPH 60, que apresentou raízes com diâmetro de batata-doce do tipo extra A, podem ser indicados para compor programas de intercruzamentos, visando obter genótipos superiores.

Palavras-chave: Ipomoea batatas, dissimilaridade, Análise por Agrupamento Hierárquico, Análise por Componentes Principais, parâmetros populacionais, melhoramento.

\section{ABSTRACT}

Genetic divergence of sweet potato accessions based on morpho-agronomic descriptors of the roots

Knowledge of the genetic divergence in a set of genotypes is of great importance in breeding programs to avoid similar genetic combinations, with a consequent increase of heterotic expression in hybrids and genetic gains in segregating generations. We characterized morpho-agronomically 23 genotypes of sweet potato of the Embrapa Hortaliças' germplasm bank, to use these characteristics to assess the genetic variability among the genotypes by application of the methods Hierarchical Cluster Analysis (HCA) and Principal Component Analysis (PCA) and to estimate population parameters. The experiment was carried out at Fazenda Água Limpa, owned by Universidade de Brasilia ( Brasilia University, UnB), Brasilia, Brazil. Plants were cultivated in field conditions on a randomized blocks design with four replications. Eight characteristics of the roots were evaluated. The coefficients of genetic $\left(\mathrm{CV}_{\mathrm{g}}\right)$ and environmental $\left(\mathrm{CV}_{\mathrm{e}}\right)$ variation, the broad sense heritability $\left(\mathrm{h}_{\mathrm{a}}^{\frac{\mathrm{g}}{2}}\right)$ and the ratio $\mathrm{CV}_{\mathrm{g}}$ ' $\mathrm{CV}_{\mathrm{e}}$ indicated a favorable situation for the selection of the traits marketable yield, total yield, diameter and length of sweet potato roots. Most of the analyzed genotypes are similar with respect to the morpho-agronomic descriptors used. However, crosses between genetically dissimilar parents such as the CNPH 69 clone, which stood out by high marketable and total yield; the CNPH 80 clone, presenting good shape and moderate resistance to soil insects and the CNPH 60 clone, which showed roots with ideal diameter for commercialization, can be recommended for inclusion in intercross programs aiming to generate superior genotypes.

Keywords: Ipomoea batatas, dissimilarity, Hierarchical Cluster Analysis, Principal Component Analysis, population parameters, breeding.

(Recebido para publicação em 17 de março de 2014; aceito em 12 de dezembro de 2014) (Received on March 17, 2014; accepted on December 12, 2014)

\begin{abstract}
A b a t a t a-doce (I pomoea batatas) pertencente à família Convolvulaceae, é uma espécie hexaplóide com 90 cromossomos $(2 \mathrm{n}=$ $6 x=90$ ), que teve origem na América Tropical, e atualmente é cultivada em todas as zonas tropicais, subtropicais e temperadas do mundo (Roesler et al., 2008; Castro et al., 2009).
\end{abstract}

É a sexta cultura alimentícia mais importante do mundo, com produção global por ano de mais de 105 milhões de toneladas, $95 \%$ das quais são cultivadas em países em desenvolvimento (CIP, 2013). Apresenta grande aceitação popular e relevância econômica, pois apesar do baixo custo de produção, quando bem conduzida, oferece retorno relativamente alto, sendo cultivada principalmente por pequenos agricultores.

Seu cultivo está distribuído por todo o Brasil, o que se deve, além da riqueza nutricional, à ampla adaptação a diferentes tipos de solo e clima, à facilidade de cultivo e manutenção, à possibilidade de mecanização, à proteção do solo, à alta tolerância à seca, à baixa incidência de 
pragas ou doenças limitantes, à pouca resposta à aplicação de fertilizantes, à alta eficiência fotossintética e à baixa exigência em manejo (Silva et al., 2004; Roesler et al., 2008; Feltran \& Fabri, 2010; Andrade Júnior et al., 2012).

O Brasil é o $18^{\circ}$ maior produtor mundial de batata-doce, com uma produção anual em 2012 de 479.425 t, obtida em uma área plantada de 40.120 ha (FAO, 2012; IBGE, 2012). Embora o Nordeste apresente a maior área plantada (16.717 ha) seu rendimento médio de 8,78 t/haé baixo quando comparado com o da região Sul, com uma produtividade média de $13,86 \mathrm{t} /$ ha, que representa $47,85 \%$ da produção nacional, obtida em uma área plantada de 16.560 ha. Já as regiões Sudeste e Centro-Oeste, apresentam os maiores rendimentos médios por área do país, com 15,84 t/ha e 27,99 t/ha, respectivamente, de acordo com dados do IBGE (2012).

Apesar disto, a produtividade média brasileira de 12,19 t/ha é considerada baixa, principalmente porque a maioria das cultivares não expressa todo o seu potencial genético; o que está associado a fatores como sistema de plantio inadequado, cultivo com materiais de baixo potencial produtivo, uso inadequado de ramas no plantio, plantio em solos de baixa fertilidade natural e baixo nível técnico (Castro et al., 2009; Feltran \& Fabri, 2010).

Devido ao seu elevado nível de ploidia, a batata-doce cultivada no território nacional apresenta grande diversidade fenotípica e genotípica, que precisa ser preservada e estudada para contribuir com futuros programas de melhoramento genético (Daros et al., 2002; Borges et al., 2009).

Estudos de divergência genética entre acessos de uma cultura são importantes para analisar a variabilidade genética existente na coleção do melhorista, identificar materiais genéticos muito próximos ou duplicados e fornecer parâmetros para a escolha de genitores geneticamente diferentes que, ao serem cruzados, possibilitem maior efeito heterótico, aumentando as chances de obtenção de máxima variabilidade genética e genótipos superiores em gerações segregantes (Oliveira et al., 2000; Paixão et al., 2008).
A caracterização morfológica de um banco de germoplasma é normalmente a forma mais acessível de quantificar sua diversidade genética (Ritschel \& Huamán, 2002). Esta consiste em fornecer uma identidade para cada entrada através do conhecimento de uma série de dados que permitam estudar a variabilidade genética de cada amostra (Daros et al., 2002). Já a caracterização agronômica consiste em avaliar características desejáveis pelo agricultor e que atendam ao mercado consumidor (Fabri, 2009).

Quando a caracterização é realizada por meio de dados morfológicos, a quantificação da diversidade entre acessos só terá significado se a divergência fenotípica refletir a divergência genética (Buzar et al., 2007). Estimativas relativamente altas de herdabilidade de algumas das características utilizadas como descritores de batata-doce aumentam a confiança na utilização dessas variáveis no processo de caracterização (Ritschel \& Huamán, 2002). No caso da batata-doce, a herdabilidade no sentido amplo é importante devido aos efeitos de dominância e epistasia serem mantidos pela propagação vegetativa (Gonçalves Neto et al., 2012).

Para analisar a diversidade genética e para a seleção dos descritores mais relevantes, encontram-se disponíveis vários procedimentos estatísticos multivariados, em que diversos caracteres avaliados podem ser dimensionados simultaneamente nos genótipos. $\mathrm{O}$ estudo de divergência feito por análise de agrupamento tem a finalidade de reunir, por algum critério de similaridade ou dissimilaridade, os progenitores em vários grupos, de tal modo que haja maior homogeneidade dentro do grupo e maiores níveis de heterogeneidade entre os grupos (Buzar et al., 2007).

Métodos de ordenação que permitem reduzir o número original de variáveis em um novo conjunto simplificado são utilizados para o estudo de diferentes espécies cultivadas. A Análise de Componentes Principais (PCA) tem por objetivo descrever os dados, reduzindo em poucas dimensões a matriz de distâncias entre os objetos. Para tanto, considera-se um conjunto de $p$ variáveis e encontram-se combinações lineares entre elas que produzam índices não correlacionados, denominados componentes principais, os quais refletem cada um, uma "dimensão" diferente (Peroni et al., 1999).

Quanto à verificação da dissimilaridade genética baseada em caracteres fenotípicos da raiz com vistas à obtenção de variabilidade genética para características comerciais visando o melhoramento, há poucos relatos na literatura (Silva et al., 2012).

Neste contexto, o presente trabalho teve como objetivos caracterizar morfoagronômicamente 23 genótipos de batata-doce pertencentes ao banco de germoplasma mantido na Embrapa Hortaliças; utilizar estas características para avaliar a divergência genética entre os materiais; calcular a importância relativa de cada variável na discriminação mediante uma análise de componentes principais (PCA) e estimar parâmetros populacionais.

\section{MATERIAL E MÉTODOS}

O experimento foi instalado na Fazenda Água Limpa, pertencente à Universidade de Brasília, localizada no Núcleo Rural Vargem Bonita ao Sul de Brasília-DF (1556'S, 4755'O, altitude $1.100 \mathrm{~m})$.

O solo da área experimental foi classificado como Latossolo Vermelho e a análise química do mesmo apresentou: $\mathrm{pH}$ (água) $=6,4 ; \mathrm{P}=4,8 \mathrm{mg} / \mathrm{dm}^{3} ; \mathrm{Ca}=$ $2,8 \mathrm{cmol}_{\mathrm{c}} / \mathrm{dm}^{3} ; \mathrm{Mg}=1,8 \mathrm{cmol}_{\mathrm{c} /} \mathrm{dm}^{3} ; \mathrm{K}=$ $0,27 \mathrm{cmol}_{\mathrm{c}} / \mathrm{dm}^{3} ; \mathrm{Na}=0,03 \mathrm{cmol} / \mathrm{dm}^{3}$; $\mathrm{Al}=0 \mathrm{cmol}_{\mathrm{c}} / \mathrm{dm}^{3} ; \mathrm{H}+\mathrm{Al}=2,7 \mathrm{cmol}_{\mathrm{c}}^{\mathrm{c}} / \mathrm{dm}^{3}$; $\mathrm{SB}=4,9 \mathrm{cmol}_{\mathrm{c}} / \mathrm{dm}^{3} ; \mathrm{T}=8 \mathrm{cmol} / \mathrm{dm}^{3} ; \mathrm{V}=$ $64 \% ; \mathrm{m}=0 \%$; ISNa $=0,4 \% ; \mathrm{C}=25,8 \mathrm{~g} /$ $\mathrm{kg} ; \mathrm{MO}=44,4 \mathrm{~g} / \mathrm{kg}$. Os teores de argila, areia e silte determinados pela análise granulométrica foram de 400, 475 e 125 $\mathrm{g} / \mathrm{kg}$, respectivamente. Posteriormente, procedeu-se ao preparo da área, onde foi realizada inicialmente uma aração profunda $(25 \mathrm{~cm})$. Após sete dias, foi feita uma nova aração seguida de uma gradagem. Não foi aplicado fertilizante, visto que o solo apresentou uma boa fertilidade natural.

Foram estudados 23 genótipos de batata-doce do Banco de Germoplasma mantido na Embrapa Hortaliças. O delineamento experimental utilizado foi em blocos casualizados, com 23 tratamentos 
e 4 repetições. As unidades experimentais foram constituídas de camalhões de 3,2 x 1,0 m cada, com 8 plantas por parcela, utilizando-se o espaçamento de $0,4 \mathrm{~m}$ entre plantas e de $1,0 \mathrm{~m}$ entre camalhões (Gonçalves Neto et al., 2012). Empregaram-se bordaduras nas laterais do experimento, onde foram plantadas variedades comerciais de batata-doce. Os tratamentos constituíram-se dos clones CNPH 02 (proveniente de Brazlândia-DF), CNPH 08 (Brazlândia-DF), CNPH 12 (Felixlândia-MG), CNPH 28 (Viçosa-MG), CNPH 29 (Brasília-DF), CNPH 35 (Piranga-MG), CNPH 41 (Brasília-DF), CNPH 46 (Manaus-AM), CNPH 55 (Pompeu-MG), CNPH 56 (Pompeu-MG), CNPH 59 (Brasília-DF), CNPH 60 (Argentina), CNPH 61 (Argentina), CNPH 62 (origem desconhecida), CNPH 69 (Brasília-DF), CNPH 71 (Não-Me-Toque-RS), CNPH 80 (Canguçu-RS), CNPH 87 (Campo Grande-MS), CNPH 90 (Bandeirantes-MS), CNPH 1796 (Palmeira-SC) e das cultivares comerciais Brazlândia Rosada (Brazlândia-DF), Coquinho (Brasília-DF) e Princesa (Brazlândia-DF).

Por ocasião do plantio (13/09/12) foram utilizadas ramas sadias, com 3 a 4 entrenós, dos quais 2 foram enterrados no topo da leira. Durante o desenvolvimento, na ausência de chuvas utilizou-se irrigação por aspersão, convencional por meio da aplicação de uma a lâmina de água de aproximadamente $6 \mathrm{~mm}$, com turno de rega de um dia. Foi efetuada adubação de cobertura 20 dias após o plantio com sulfato de amônio, na dose de $20 \mathrm{~g} /$ planta, e o controle de plantas espontâneas foi realizado por meio de capinas manuais com enxada. As pragas e doenças não foram controladas. Cinco meses após o plantio foi efetuada a colheita.

A produção de raízes comerciais (PC) foi obtida selecionando-se de cada parcela todas as raízes tuberosas com peso entre 100 e $800 \mathrm{~g}$, com ausência de danos e bom aspecto comercial. A produção total de raízes frescas (PT) foi calculada pela pesagem de todas as raízes de cada parcela. Os pesos foram extrapolados para $\mathrm{t} / \mathrm{ha}$.

Para a estimativa dos danos causados por insetos de solo, foi quantificado o número de furos $(\mathrm{NF})$ de 4 a 12 raízes tomadas aleatoriamente em cada parcela e avaliada a Incidência de danos (ID) segundo a escala de notas empregada por França et al. (1983), citados por Azevedo et al. (2000) e Andrade Júnior et al. (2012). Foram atribuídas notas numa escala variável de 1 a 5 , na qual a nota 1 correspondeu às raízes livres de danos causados por insetos de solo, com aspecto comercial desejável e a nota 5 foi atribuída às raízes inaceitáveis para fins comerciais. As notas foram dadas por dois avaliadores, sendo o valor final expresso pela média dos dois. De acordo com a escala de notas para a incidência de danos, classificaram-se os genótipos segundo o seu grau de resistência aos insetos de solo (GR), considerando-se como clones resistentes aqueles com nota $\leq 1$; moderadamente resistentes os genótipos com notas $\geq 1 \leq 2$; moderadamente suscetíveis os materiais com nota $\geq 2 \leq 3$; suscetíveis os clones com notas $\geq 3 \leq 4$ e altamente suscetíveis os materiais com notas $\geq 4 \leq 5$.

Obteve-se o diâmetro médio (DR) pela medição da parte intermediária transversal da raiz, com a ajuda de um paquímetro digital. O comprimento médio (CR) foi obtido medindo-se o eixo longitudinal da raiz com o uso de uma régua plástica graduada. A espessura média do córtex (EC) foi calculada pela medição da casca na porção mediana das raízes cortadas, com o auxilio de um paquímetro digital.

O formato das raízes tuberosas (FT) foi obtido por meio de uma escala de notas entre 1 e 5, estabelecida por França et al. (1983) e empregada por Azevedo et al. (2000) e Andrade Júnior et al. (2012). Foram avaliadas entre 4 e 12 raízes tomadas aleatoriamente em cada parcela, considerando-se como nota a média das raízes avaliadas. As notas foram dadas por dois avaliadores, sendo o valor final expresso pela média das duas notas. A nota 1 foi conferida às raízes com formato fusiforme, regular, sem veias ou qualquer rachadura e a nota 5 foi conferida às raízes totalmente fora dos padrões comerciais, muito irregulares, deformadas, curvas e com muitas veias e rachaduras.

Os dados foram submetidos à análise de variância para cada caráter e as médias foram agrupadas por meio do teste de Scott-Knott, a 5\% de probabilidade. Com exceção das características DR e FT, todos os dados foram transformados em $\sqrt{x+1}$, sendo apresentados os valores originais. Com a utilização dos caracteres quantitativos foram efetuadas análises de diversidade entre os acessos por meio de medidas baseadas na distância Euclidiana. Para o agrupamento hierárquico $(\mathrm{AAH})$ foi obtido o dendrograma para os pares ordenados pela média aritmética não ponderada (UPGMA). Posteriormente, foi realizada uma análise de componentes principais (PCA) sobre uma matriz de correlação. As análises estatísticas descritas anteriormente foram realizadas utilizando-se o software R Core Team (2013).

A partir dos componentes da variância foram estimados os parâmetros genéticos de herdabilidade no sentido amplo $\left(\mathrm{h}_{\mathrm{a}}^{2}\right)$, os coeficientes de variação genético $\left(\mathrm{CV}_{\mathrm{g}}\right)$, ambiental $\left(\mathrm{CV}_{\mathrm{e}}\right)$ e a razão entre os coeficientes de variação genético e ambiental $\left(\mathrm{CV}_{\mathrm{g}} / \mathrm{CV}_{\mathrm{e}}\right)$ para os caracteres estudados, utilizando-se o programa GENES (Cruz, 2013).

\section{RESULTADOS E DISCUSSÃO}

Verificou-se a existência de diferenças significativas entre os genótipos a $1 \%$ de probabilidade pelo teste $\mathrm{F}$ para os caracteres em estudo, o que possibilitou diferenciar os clones avaliados (Tabela 1). Diferenças significativas foram apontadas pelo teste de Scott-Knott a 5\% de probabilidade entre as médias dos 23 genótipos para cada característica analisada, indicando diversidade genética.

Foi observada grande amplitude de variação na produtividade comercial $(0 \mathrm{a}$ 47,12 t/ha), sendo que o clone CNPH 12 não apresentou raízes comerciais. A cultivar Brazlândia Rosada $(27,28$ t/ha) e os clones CNPH 46 (29,36 t/ha), CNPH $59(32,91 \mathrm{t} / \mathrm{ha})$, CNPH 60 (36,22 t/ha) e CNPH 69 (47,12 t/ha) apresentaram as maiores produtividades comerciais. As cultivares Coquinho e Princesa apresentaram produtividades comerciais de 4,13 e 12,47 t/ha, respectivamente. Peixoto et al. (1999) observaram uma produtividade comercial semelhante para a cultivar Coquinho de 4,83 t/ha. Já o valor obtido para a produtividade 
Tabela 1. Resumo das análises de variância e médias das características: $\mathrm{DR}=$ diâmetro; $\mathrm{CR}=$ comprimento; $\mathrm{EC}=$ espessura do córtex; $\mathrm{FT}=$ formato; $\mathrm{NF}=$ número de furos causados por insetos de solo por raiz; $\mathrm{ID}=$ incidência de danos; $\mathrm{GR}=$ grau de resistência $(\mathrm{MR}=$ moderadamente resistente e $\mathrm{MS}=$ moderadamente suscetível); $\mathrm{PC}=$ produtividade comercializável; $\mathrm{PT}=$ produtividade total das raízes de batata-doce \{ summary of analysis of variance and average values of the characteristics: $\mathrm{DR}=$ diameter; $\mathrm{CR}=$ length; $\mathrm{EC}=$ cortex thickness; $\mathrm{FT}=$ shape; $\mathrm{NF}=$ number of holes caused by soil insects per root; $\mathrm{ID}=$ damage incidence; $\mathrm{GR}=$ resistance degree $(\mathrm{MR}=$ moderately resistant and $\mathrm{MS}=$ moderately susceptible); $\mathrm{PC}=$ marketable yield; $\mathrm{PT}=$ total yield, of sweet potato roots $\}$. Brasília, UnB, 2013.

\begin{tabular}{|c|c|c|c|c|c|c|c|c|c|}
\hline Genótipo & DR (cm) & CR (cm) & $\mathrm{EC}(\mathrm{mm})$ & FT $^{1}$ & $\mathbf{N F}$ & ID $^{2}$ & GR & $\mathrm{PC}(\mathrm{t} / \mathrm{ha})$ & PT (t/ha) \\
\hline CNPH69 & $3,77 \mathrm{c}$ & $38,30 \mathrm{a}$ & $2,97 \mathrm{c}$ & $2,06 \mathrm{~b}$ & $20,65 \mathrm{a}$ & $1,78 \mathrm{a}$ & MR & $47,12 \mathrm{a}$ & $47,54 \mathrm{a}$ \\
\hline CNPH46 & $6,40 \mathrm{~b}$ & $24,41 \mathrm{~b}$ & $2,91 \mathrm{c}$ & $3,83 \mathrm{a}$ & $19,99 \mathrm{a}$ & $1,96 \mathrm{a}$ & MR & $29,36 \mathrm{a}$ & $38,36 \mathrm{a}$ \\
\hline CNPH60 & $6,55 \mathrm{~b}$ & $17,39 \mathrm{c}$ & $3,29 \mathrm{~b}$ & $2,68 \mathrm{~b}$ & $5,93 \mathrm{~b}$ & $1,17 \mathrm{~b}$ & MR & $36,22 \mathrm{a}$ & $36,56 \mathrm{a}$ \\
\hline CNPH59 & $5,76 \mathrm{~b}$ & $17,81 \mathrm{c}$ & $2,21 \mathrm{~d}$ & $2,46 \mathrm{~b}$ & $17,40 \mathrm{a}$ & $1,73 \mathrm{a}$ & MR & $32,91 \mathrm{a}$ & $33,54 \mathrm{a}$ \\
\hline Brazlândia Rosada & $5,77 \mathrm{~b}$ & $15,40 \mathrm{c}$ & $2,57 \mathrm{c}$ & $2,38 \mathrm{~b}$ & $14,97 \mathrm{a}$ & $1,89 \mathrm{a}$ & MR & $27,28 \mathrm{a}$ & $28,57 \mathrm{a}$ \\
\hline CNPH56 & $9,03 \mathrm{a}$ & $19,42 \mathrm{c}$ & $3,40 \mathrm{~b}$ & $3,01 \mathrm{a}$ & $12,13 \mathrm{a}$ & $1,61 \mathrm{~b}$ & MR & $24,06 \mathrm{~b}$ & $25,71 \mathrm{a}$ \\
\hline CNPH02 & $5,52 \mathrm{~b}$ & $17,13 \mathrm{c}$ & $2,79 \mathrm{c}$ & $2,25 \mathrm{~b}$ & $16,86 \mathrm{a}$ & $1,92 \mathrm{a}$ & MR & $19,65 \mathrm{~b}$ & $25,03 \mathrm{a}$ \\
\hline CNPH80 & $5,09 \mathrm{c}$ & $16,94 \mathrm{c}$ & $2,58 \mathrm{c}$ & $1,94 \mathrm{~b}$ & $9,19 \mathrm{~b}$ & $1,32 \mathrm{~b}$ & MR & $20,09 \mathrm{~b}$ & $23,69 \mathrm{a}$ \\
\hline Princesa & $5,44 \mathrm{~b}$ & $19,15 \mathrm{c}$ & $4,20 \mathrm{a}$ & $2,93 \mathrm{a}$ & $18,89 \mathrm{a}$ & $1,93 \mathrm{a}$ & MR & $12,47 \mathrm{c}$ & $17,45 \mathrm{a}$ \\
\hline CNPH08 & $5,93 \mathrm{~b}$ & $11,40 \mathrm{~d}$ & $2,80 \mathrm{c}$ & $2,56 \mathrm{~b}$ & $10,25 \mathrm{~b}$ & $1,38 \mathrm{~b}$ & MR & $16,84 \mathrm{~b}$ & $17,53 \mathrm{~b}$ \\
\hline CNPH90 & $4,82 \mathrm{c}$ & $14,70 \mathrm{c}$ & $2,42 \mathrm{~d}$ & $2,68 \mathrm{~b}$ & $4,76 \mathrm{~b}$ & $1,13 \mathrm{~b}$ & MR & $14,06 \mathrm{c}$ & $14,81 \mathrm{~b}$ \\
\hline CNPH35 & $8,26 \mathrm{a}$ & $21,77 \mathrm{c}$ & $3,99 \mathrm{a}$ & $2,51 \mathrm{~b}$ & $20,06 \mathrm{a}$ & $2,45 \mathrm{a}$ & MS & $6,31 \mathrm{c}$ & $13,63 \mathrm{~b}$ \\
\hline CNPH1796 & $4,02 \mathrm{c}$ & $11,68 \mathrm{~d}$ & $2,07 \mathrm{~d}$ & $1,77 \mathrm{~b}$ & $7,35 \mathrm{~b}$ & $1,26 \mathrm{~b}$ & MR & $7,84 \mathrm{c}$ & $11,51 \mathrm{~b}$ \\
\hline CNPH55 & $5,77 \mathrm{~b}$ & $7,66 \mathrm{~d}$ & $2,72 \mathrm{c}$ & $3,12 \mathrm{a}$ & $13,03 \mathrm{a}$ & $1,46 \mathrm{~b}$ & MR & $10,69 \mathrm{c}$ & $11,22 \mathrm{~b}$ \\
\hline CNPH62 & $5,51 \mathrm{~b}$ & $10,48 \mathrm{~d}$ & $2,76 \mathrm{c}$ & $2,37 \mathrm{~b}$ & $15,67 \mathrm{a}$ & $1,54 \mathrm{~b}$ & MR & $8,20 \mathrm{c}$ & $10,76 \mathrm{~b}$ \\
\hline CNPH41 & $6,09 \mathrm{~b}$ & $9,44 d$ & $2,99 \mathrm{c}$ & $2,33 \mathrm{~b}$ & $6,56 \mathrm{~b}$ & $1,22 \mathrm{~b}$ & MR & $9,39 \mathrm{c}$ & $10,02 \mathrm{~b}$ \\
\hline CNPH28 & $4,66 \mathrm{c}$ & $11,15 \mathrm{~d}$ & $2,36 \mathrm{~d}$ & $3,44 \mathrm{a}$ & $16,71 \mathrm{a}$ & $2,34 \mathrm{a}$ & MS & $6,64 \mathrm{c}$ & $7,87 \mathrm{~b}$ \\
\hline CNPH87 & $3,97 \mathrm{c}$ & $11,17 \mathrm{~d}$ & $2,39 \mathrm{~d}$ & $2,69 \mathrm{~b}$ & $8,25 \mathrm{~b}$ & $1,31 \mathrm{~b}$ & MR & $6,80 \mathrm{c}$ & $7,72 \mathrm{~b}$ \\
\hline CNPH61 & $5,25 \mathrm{c}$ & $8,88 \mathrm{~d}$ & $2,86 \mathrm{c}$ & $3,17 \mathrm{a}$ & $18,10 \mathrm{a}$ & $1,78 \mathrm{a}$ & MR & $1,31 \mathrm{c}$ & $6,69 \mathrm{~b}$ \\
\hline CNPH29 & $3,81 \mathrm{c}$ & $19,48 \mathrm{c}$ & $1,97 \mathrm{~d}$ & $2,69 \mathrm{~b}$ & $7,11 \mathrm{~b}$ & $1,29 \mathrm{~b}$ & MR & $5,63 \mathrm{c}$ & $6,23 \mathrm{~b}$ \\
\hline Coquinho & $3,43 \mathrm{c}$ & $11,67 \mathrm{~d}$ & $2,29 \mathrm{~d}$ & $2,31 \mathrm{~b}$ & $3,44 \mathrm{~b}$ & $1,09 \mathrm{~b}$ & MR & $4,13 \mathrm{c}$ & $6,22 \mathrm{~b}$ \\
\hline CNPH71 & $4,00 \mathrm{c}$ & $6,75 \mathrm{~d}$ & $2,40 \mathrm{~d}$ & $2,00 \mathrm{~b}$ & $19,10 \mathrm{a}$ & $2,14 \mathrm{a}$ & MS & $2,81 \mathrm{c}$ & $4,44 \mathrm{~b}$ \\
\hline CNPH12 & $6,49 \mathrm{~b}$ & $17,03 \mathrm{c}$ & $3,19 \mathrm{~b}$ & $3,12 \mathrm{a}$ & $19,33 \mathrm{a}$ & $2,37 \mathrm{a}$ & MS & $0,00 \mathrm{c}$ & $0,78 \mathrm{~b}$ \\
\hline $\mathrm{QM}_{\text {(tratamento) }}$ & $764,16^{*}$ & $23,57 *$ & $0,08^{*}$ & $1,01^{*}$ & $2,47 *$ & $0,06^{*}$ & - & $9,94^{*}$ & $7,97^{*}$ \\
\hline Média & 5,45 & 15,62 & 2,79 & 2,62 & 13,29 & 1,66 & - & 15,20 & 17,65 \\
\hline
\end{tabular}

* Médias com a mesma letra na coluna não diferem entre si, pelo teste de Scott-Knott a 5\% de probabilidade (means with the same letter in column are not different by the Scott-Knott test at 5\%); * significativo a $1 \%$ de probabilidade pelo teste $\mathrm{F}$ (significant at $1 \%$ by $\mathrm{F}$ test); ${ }^{1}$ notas do formato das raízes ( $1=$ fusiforme; $2=$ semelhante ao fusiforme, com algumas veias; $3=$ desuniforme, com veias e muito irregulares; $4=$ raízes muito grandes, com veias e rachaduras, comercialmente inadequadas; $5=$ completamente fora do padrão comercial, muito irregulares e deformadas, com muitas veias e rachaduras) (root shape grades $(1=$ spindle-shaped; $2=$ close to spindle-shaped, with some veins; $3=$ uneven, with veins and very irregular spape; $4=$ very large roots, with veins and cracks, undesirable for the market; $5=$ completely out of the commercial standard, very irregular spape and deformed roots, with many veins and cracks) $\}$; ${ }^{2}$ notas para a incidência de danos nas raízes causados por insetos de solo ( $1=$ livres de danos; 2 = poucos danos, presença de alguns furos e galerias; $3=$ muitos furos e galerias; $4=$ muito danificadas, praticamente inadequadas para comercialização; $5=$ completamente inadequadas para comercialização) \{grades for damage incidence in the roots caused by soil insects ( $1=$ free of damage; $2=$ little damage but presence of some holes and galleries; $3=$ many holes and galleries; $4=$ very damaged, practically unsuitable for the market; $5=$ completely unsuitable for the market) $\}$.

média da cultivar Princesa foi superior à produtividade atingida por Viana (2009), com colheita realizada aos cinco meses (11,96 t/ha). Com relação à cultivar Brazlândia Rosada, Figueiredo (2010), avaliando 12 clones de batata-doce em Diamantina-MG, obteve uma produtividade comercial média de raízes na faixa de 11,52 a 28,85 t/ha, sendo que a cultivar Brazlândia Rosada apresentou $24,52 \mathrm{t} / \mathrm{ha}$, valor este condizente ao observado no presente estudo.

Os clones com maior produção total de raízes frescas foram $\mathrm{CNPH}$ $69(47,54 \mathrm{t} / \mathrm{ha})$, CNPH $46(38,36 \mathrm{t} /$ ha), CNPH 60 (36,56 t/ha) e CNPH $59(33,54 \mathrm{t} / \mathrm{ha})$. Contudo, não foram observadas diferenças estatisticamente significativas entre estes materiais e as cultivares Princesa e Brazlândia Rosada (17,45 e 28,57 t/ha, respectivamente) e os clones CNPH 80, CNPH 02 e CNPH $56(23,69 ; 25,03$ e $25,71 \mathrm{t} / \mathrm{ha}$, respectivamente). A produtividade média total $(17,65 \mathrm{t} / \mathrm{ha})$ foi superior à produtividade média brasileira de 12,19 t/ha (IBGE, 2012) e às produtividades atingidas por 
Tabela 2. Estimativas da herdabilidade no sentido amplo $\left(\mathrm{h}_{\mathrm{a}}^{2}\right)$, coeficiente de variação genético $\left(\mathrm{CV}_{\mathrm{g}}\right)$, coeficiente de variação ambiental $\left(\mathrm{CV}_{\mathrm{e}}\right)$ e razão entre coeficiente de variação genético e ambiental $\left(\mathrm{CV}_{\mathrm{g}} / \mathrm{CV}_{\mathrm{e}}\right)$ em caracteres de clones de batata-doce \{estimates of broad sense heritabilities $\left(\mathrm{h}_{\mathrm{a}}^{2}\right)$, genetic variation coefficients $\left(\mathrm{CV}_{\mathrm{g}}\right)$, environmental variation coefficients $\left(\mathrm{CV}_{\mathrm{e}}\right)$ and ratio between genetic/envirornmental variation coefficients $\left(\mathrm{CV}_{\mathrm{g}} / \mathrm{CV}_{\mathrm{e}}\right)$ for sweet potato clones traits\}. Brasília, UnB, 2013.

\begin{tabular}{lcccccccc}
\hline Parâmetros & $\begin{array}{c}\text { Diâmetro } \\
(\mathbf{m m})\end{array}$ & $\begin{array}{c}\text { Comprimento } \\
\mathbf{( m m})\end{array}$ & $\begin{array}{c}\text { Espessura do } \\
\text { córtex }(\mathbf{m m})\end{array}$ & Formato $^{1}$ & $\begin{array}{c}\text { Número de } \\
\text { furos/raiz }^{2}\end{array}$ & $\begin{array}{c}\text { Incidência } \\
\text { de danos }^{2}\end{array}$ & \multicolumn{2}{c}{ Produtividade (t/ha) } \\
\hline $\mathrm{h}_{\mathrm{a}}^{2}(\%)$ & 85,42 & 85,34 & 78,62 & 74,77 & 59,00 & 65,76 & 81,55 & 75,50 \\
$\mathrm{CV}_{\mathrm{g}}(\%)$ & 23,46 & 18,38 & 6,34 & 16,60 & 16,82 & 6,27 & 39,73 & 31,66 \\
$\mathrm{CV}_{\mathrm{e}}(\%)$ & 19,39 & 15,24 & 6,62 & 19,28 & 28,04 & 9,05 & 37,80 & 34,11 \\
$\mathrm{CV}_{\mathrm{g}} / \mathrm{CV}$ & 1,21 & 1,21 & 0,96 & 0,86 & 0,60 & 0,69 & 1,05 & 0,93 \\
\hline
\end{tabular}

${ }^{1}$ Notas do formato das raízes ( 1 = fusiforme; 2 = semelhante ao fusiforme, com algumas veias; 3 = desuniforme, com veias e muito irregulares; $4=$ raízes muito grandes, com veias e rachaduras, comercialmente inadequadas; $5=$ completamente fora do padrão comercial, muito irregulares e deformadas, com muitas veias e rachaduras) \{root shape grades ( $1=$ spindle-shaped; 2 = close to spindle-shaped, with some veins; $3=$ uneven, with veins and very irregular shape; $4=$ very large roots, with veins and cracks, undesirable for the market; $5=$ completely out of the commercial standard, very irregulars and deformed roots, with many veins and cracks) $\} ;{ }^{2}$ notas para a incidência de danos nas raízes causados por insetos de solo ( $1=$ livres de danos; $2=$ poucos danos, presença de alguns furos e galerias; $3=$ muitos furos e galerias; $4=$ muito danificadas, praticamente inadequadas para comercialização; $5=$ completamente inadequadas para comercialização) \{grades for damage incidence in the roots caused by soil insects ( $1=$ free of damage; $2=$ little damage but presence of some holes and galleries; $3=$ many holes and galleries; $4=$ very damaged, practically unsuitable for the market; $5=$ completely unsuitable for the market\}.

Cavalcante et al. (2009), com colheita aos 130 dias $(6,29 \mathrm{t} / \mathrm{ha})$ e às alcançadas por Cardoso et al. (2005) e Massaroto et al. (2014), com colheita aos 6 meses (15,22 e 14,59 t/ha, respectivamente). Além da duração do ciclo dos materiais, das condições edafoclimáticas do local de cultivo, da época de plantio, da qualidade das estacas utilizadas e do tempo de permanência da cultura no campo, constituintes genéticos das cultivares e fatores como a temperatura, fotoperíodo e radiação solar incidente, que resultam na interação entre genótipos e ambientes, afetam diretamente o crescimento, desenvolvimento e tamanho das raízes e, consequentemente, o rendimento das cultivares (Barreto et al., 2011; Erpen et al., 2013).

A média geral do diâmetro das raízes para os genótipos estudados foi de 5,45 $\mathrm{cm}$. A cultivar Coquinho $(3,43 \mathrm{~cm})$ foi a que apresentou o menor diâmetro; porém, não diferiu estatisticamente dos materiais CNPH 69, CNPH 29, CNPH 71, CNPH 87, CNPH 1796, CNPH 28, CNPH 90, CNPH 80 e CNPH 61 $(37,71 ; 3,81 ; 4,0 ; 39,7 ; 4,02 ; 4,66 ; 4,82$; 5,09 e $5,25 \mathrm{~cm}$, respectivamente). Já o maior diâmetro foi verificado nos clones CNPH 35 (8,26 cm) e CNPH 56 (9,03 $\mathrm{cm}$ ) (Tabela 1). Resultados semelhantes foram obtidos por Silva et al. (2012), que observaram diâmetros entre 5,62 (345-B) e $9,78 \mathrm{~cm}$ (1270) seis meses após o plantio. Ainda, segundo Miranda et al. (1995), as raízes de batata-doce do tipo extra A (melhor classificação) devem apresentar diâmetro entre 5,0 e 8,0 $\mathrm{cm}$. No presente trabalho, $56,52 \%$ dos materiais estudados mostraram valores na faixa ideal, sendo, portanto, promissores. Contudo, segundo Cavalcante et al. (2009), a classificação da batata-doce no mercado atacadista é caracterizada pela cor de sua casca, polpa, pela sua massa e pela sua qualidade, e não se levam em consideração nem o comprimento nem o diâmetro das raízes.

O comprimento das raízes variou entre 6,75 (clone CNPH 71) e 38,30 cm (clone CNPH 69). Apenas o clone CNPH $90(14,70 \mathrm{~cm})$ e a cultivar Brazlândia Rosada $(15,40 \mathrm{~cm})$ se enquadraram no comprimento ideal de raízes de batata-doce (classificação extra A) proposto por Miranda et al. (1995), o qual deve variar entre 12 e $16 \mathrm{~cm}$. Contudo, estes genótipos não apresentaram diferença significativa com os clones CNPH 80 (16,94 cm), CNPH 12 (17,03 $\mathrm{cm}), \mathrm{CNPH} 02(17,13 \mathrm{~cm}), \mathrm{CNPH}$ $60(17,39 \mathrm{~cm})$, CNPH $59(17,81 \mathrm{~cm})$, CNPH 56 (19,42 cm), CNPH 29 (19,48 $\mathrm{cm})$, CNPH $35(21,77 \mathrm{~cm})$ e a cultivar Princesa $(19,15 \mathrm{~cm})$, que mostraram valores de comprimento muito próximos à Classificação extra $\mathrm{A}$.

A espessura do córtex das raízes variou de $1,97 \mathrm{~mm}$, para o clone $\mathrm{CNPH}$
29, a 4,20 mm, para a cultivar Princesa (Tabela 1). Estes valores se encontram próximos dos observados por Cavalcante et al. (2009) que obtiveram espessuras do córtex entre 2,00 e 4,67 mm, para os clones CL-06 e CL-09, respectivamente. De acordo com estes autores, é possível que raízes que apresentem espessura de córtex mais grossa sejam favorecidas na ocasião do transporte e armazenamento, porém o rendimento da polpa da raiz (massa da polpa sem o córtex) pode ser reduzido.

Com exceção dos clones CNPH 46, CNPH 28, CNPH 61, CNPH 55, CNPH 12 e CNPH 56, todos os genótipos apresentaram nota de formato inferior a $3,0(73,91 \%$ dos materiais analisados $)$, variando de 1,77 (CNPH 1796) a 2,93 (Princesa), sendo considerados bastante promissores, especialmente aqueles que mais se aproximaram do formato ideal fusiforme (notas de 1 a 2). Apesar do bom rendimento total do clone $\mathrm{CNPH}$ 46 (38,36 t/ha), o mesmo apresentou formato não desejável $(3,83)$ podendo ser empregado para procesamento industrial ou alimentação animal. De acordo com Azevedo et al. (2000), o formato é uma das características importantes estudadas em programas de melhoramento de batata-doce. As cultivares Brazlândia Rosada $(2,38)$ e Coquinho $(2,31)$ apresentaram formatos semelhantes, porém melhores, aos reportados por Azevedo 


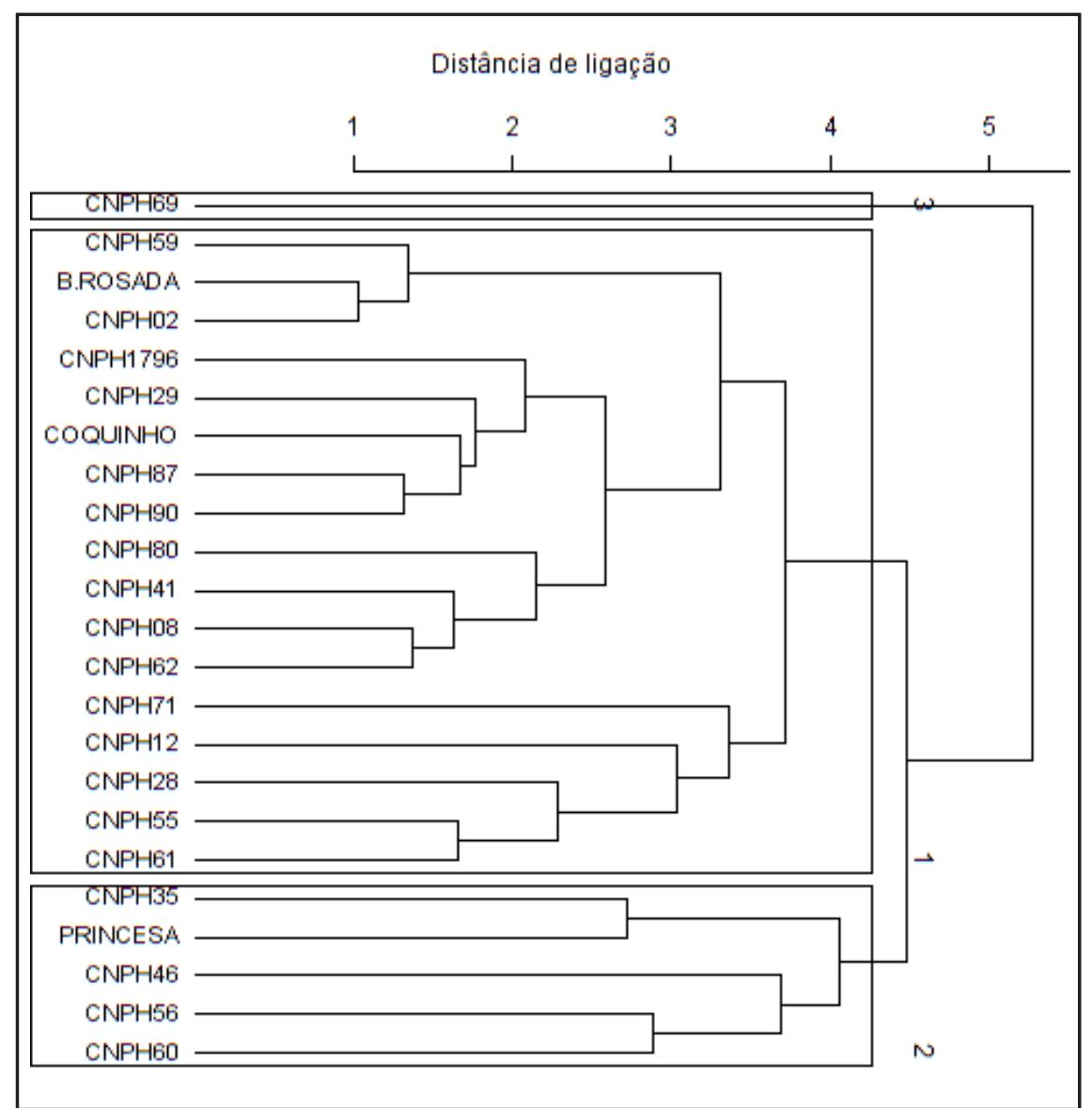

Figura 1. Dendrograma de dissimilaridade de 23 clones de batata-doce, estabelecido pelo método UPGMA utilizando-se a distância Euclidiana, com base em 8 caracteres morfoagronômicos (dissimilarity dendrogram of 23 sweet potato clones, established by the UPGMA method using the Euclidean distance, based on 8 morphoagronomic characters). Brasília, UnB, 2013.

Tabela 3. Matriz de correlação entre as variáveis analisadas e as dimensões da análise de componentes principais (correlation matrix between the variables analyzed and the dimensions of principal component analysis with significance of $\mathrm{p}<0.05$ ). Brasília, UnB, 2013.

\begin{tabular}{lcccc}
\hline Variáveis & CP1 & CP2 & CP3 & CP4 \\
\hline Produção de raízes comerciais & $-0,58$ & 0,77 & n.s. & n.s. \\
Produção total de raízes frescas & $-0,63$ & 0,74 & n.s. & n.s. \\
Furos causados por insetos do solo $\left(\mathrm{n}^{\mathrm{o}}\right)$ & $-0,70$ & $-0,45$ & $-0,50$ & n.s. \\
Incidência de danos & $-0,59$ & $-0,64$ & $-0,45$ & n.s. \\
Diâmetro médio da raiz & $-0,65$ & n.s. & 0,58 & n.s. \\
Comprimento médio da raiz & $-0,73$ & n.s. & n.s. & n.s. \\
Espessura média do córtex & $-0,71$ & n.s. & n.s. & n.s. \\
Formato das raízes tuberosas & n.s. & $-0,42$ & n.s. & $-0,74$ \\
\hline Autovalores & 3,16 & 2,22 & 1,09 & 0,76 \\
Variância explicada (\%) & 39,50 & 27,79 & 13,62 & 9,51 \\
Variância acumulativa & 39,50 & 67,28 & 80,90 & 90,41 \\
\hline CP1 prim
\end{tabular}

$\mathrm{CP} 1=$ primeiro componente principal (first principal component); $\mathrm{CP} 2=$ segundo componente principal (second principal component); $\mathrm{CP} 3=$ terceiro componente principal (third principal component); $\mathrm{CP} 4=$ quarto componente principal (fourth principal component); n.s.: não significativo a $5 \%$ de probabilidade (not significant at $\mathrm{p}<0.05$ ).
(1995), que obteve notas 2,57 e 2,93, respectivamente.

Aproximadamente $34,78 \%$ dos materiais apresentaram em média menos de 10 furos por raiz, sendo que a cultivar Coquinho apresentou apenas 3,4 furos (Tabela 1). Já os clones CNPH 69 e CNPH 35, foram os mais furados pelos insetos de solo com 20,65 e 20,06 furos por raiz, respectivamente. Apenas os clones CNPH 35, CNPH 12, CNPH 28 e CNPH 71 apresentaram notas de incidência de danos superiores a 2 , sendo considerados moderadamente suscetíveis. Contudo, não houve diferença significativa com relação à incidência de danos e número de furos, entre estes materiais e os genótipos CNPH 46, CNPH 02, Princesa, CNPH 61, Brazlândia Rosada, CNPH 69 e CNPH 59, que foram classificados como moderadamente resistentes. Isto pode ser explicado pelo fato da incidência de danos não estar apenas correlacionada com o número de furos. A infecção secundária por outros patógenos pode resultar em degradação extensa dos tecidos previamente furados, afetando não só o aspecto comercial das raízes, mas também o seu grau de resistência.

A cultivar Brazlândia Rosada empregada com testemunha e cultivada no DF, foi moderadamente resistente aos insetos de solo com 14,97 furos em média por raiz e uma incidência de danos de 1,89 , valor semelhante ao relatado por Andrade Júnior et al. (2012) quanto à avaliação de resistência para essa cultivar $(1,8)$. As cultivares Princesa e Coquinho também foram moderadamente resistentes aos insetos de solo com uma incidência de danos de 1,93 e 1,09, respectivamente. Viana (2009) aos 150 dias do plantio verificou também uma moderada resistência das cultivares Brazlândia Rosada e Princesa, com incidência de danos média entre os dois locais avaliados de 1,57 e 1,19, respectivamente. Resultados contrastantes foram reportados por Azevedo (1995) que constatou a suscetibilidade das cultivares Brazlândia Rosada e Coquinho, com notas 2,10 e 2,37, respectivamente. Segundo este autor, as notas menores resultam da baixa incidência de insetos 


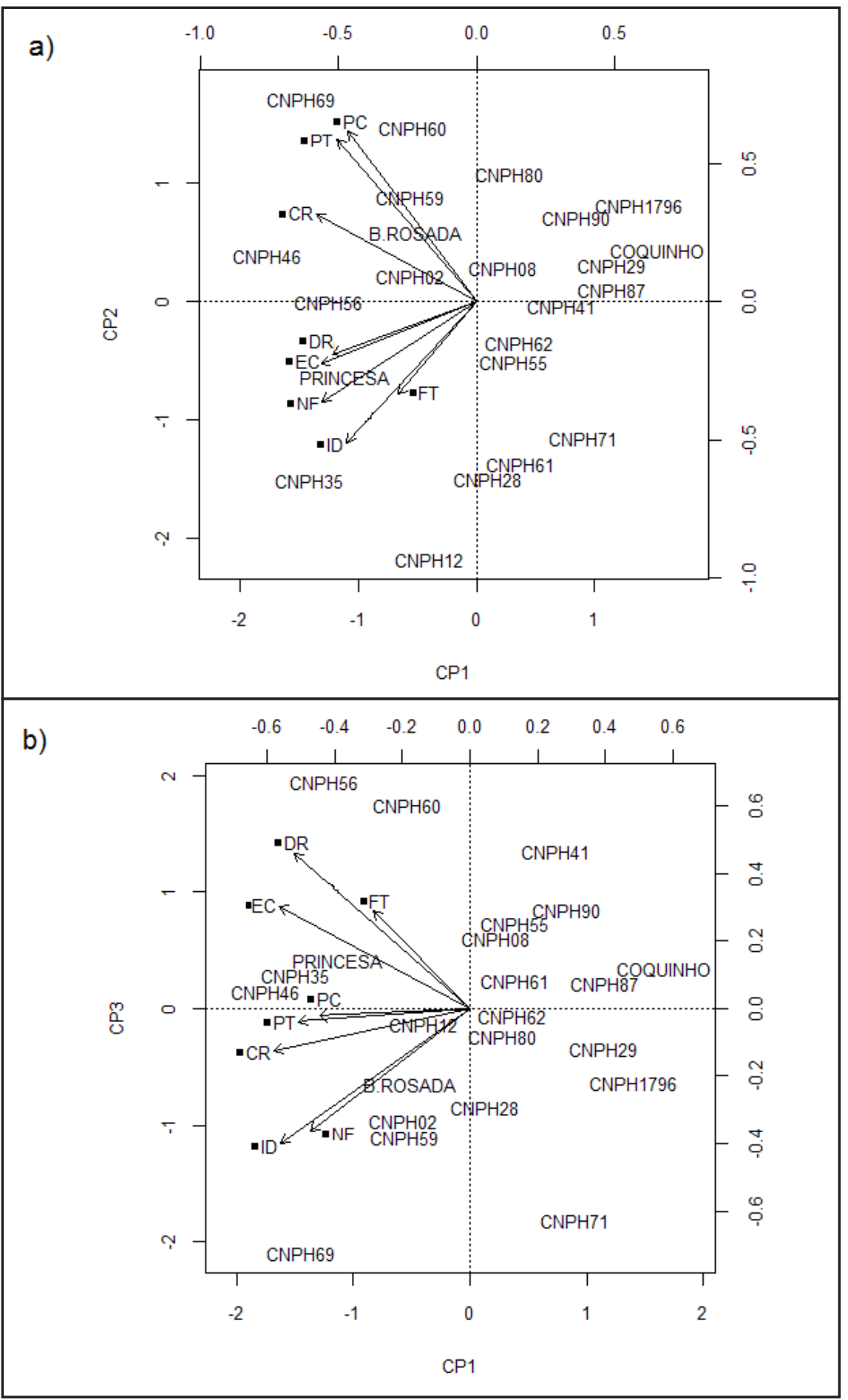

Figura 2. Gráfico biplot da Análise de Componentes Principais com as características estudadas: a) CP1 (primeiro componente principal) versus CP2 (segundo componente principal); b) CP1 (primeiro componente principal) versus CP3 (terceiro componente principal), de acordo com os três primeiros componentes principais \{Principal Component Analysis biplot with traits investigated: a) $\mathrm{CP} 1$ (first principal component) versus $\mathrm{CP} 2$ (second principal component) and b) CP1 (first principal component) versus CP3 (third principal component), according to the first three main components $\} . \mathrm{PC}=$ produtividade comercializável $(\mathrm{t} / \mathrm{ha})$ $\{$ marketable yield $(\mathrm{t} / \mathrm{ha})\} ; \mathrm{PT}=$ produtividade total $(\mathrm{t} / \mathrm{ha})\{$ total yield $(\mathrm{t} / \mathrm{ha})\} ; \mathrm{NF}=$ número de furos causados por insetos de solo por raiz (number of holes caused by soil insects per root); $\mathrm{ID}=$ incidência de danos (damage incidence); $\mathrm{DR}=$ diâmetro (diameter); $\mathrm{CR}=$ comprimento (length); $\mathrm{EC}=$ espessura do córtex (cortex thickness); $\mathrm{FT}=$ formato das raízes de batata-doce (shape, of sweet potato roots). Brasília, UnB, 2013. de solo na cultura durante a condução do experimento, que está relacionada com aplicações frequentes de irrigação. Adicionalmente, fatores ambientais e constituintes genéticos, como a quantidade de compostos fenólicos produzida nos tecidos, podem promover a resistência a insetos de solo.

$\mathrm{Na}$ Tabela 2 são apresentadas as estimativas da $\mathrm{h}_{\mathrm{a}}^{2}, \mathrm{CV}_{\mathrm{g}}, \mathrm{CV}_{\mathrm{e}}$ e a razão $\mathrm{CV}_{\mathrm{g}} / \mathrm{CV}_{\mathrm{e}}$ para os caracteres estudados. Os coeficientes de variação experimental (CVe) foram baixos para a maioria das características, demonstrando existir uma boa precisão experimental. Já os maiores valores obtidos para a produtividade comercial, produtividade total e número de furos causados por insetos de solo $(37,80,34,11$ e $28,04 \%$, respectivamente), enquadram-se dentro da faixa encontrada para estes caracteres na batata-doce. Neiva et al. (2011) reportaram $\mathrm{CV}_{\mathrm{e}}$ para a resistência a insetos do solo de 25,73\%. Cardoso et al. (2005) constataram $\mathrm{CV}_{\mathrm{e}}$ para a produtividade de raízes tuberosas de $46,64 \%$ e para a produtividade comercial de $59,02 \%$. Ainda, Queiroga et al. (2007) observaram para a produtividade total de raízes e a produtividade de raízes comerciais $\mathrm{CV}_{\mathrm{e}}$ de 36,06 e $40,12 \%$, respectivamente. De acordo com Cavalcante et al. (2012) é comum encontrar valores de coeficientes de variação elevados em variáveis relacionadas a órgãos ou estruturas subterrâneas, pois o controle do ambiente é dificultado. O coeficiente de variação genético $\left(\mathrm{CV}_{\mathrm{g}}\right)$ foi de alta magnitude para as variáveis produtividade comercial $(39,73 \%)$, produtividade total (31,66\%), diâmetro $(23,46 \%)$ e comprimento das raízes $(18,38 \%)$, indicando alta variabilidade entre os materiais com relação a estas características.

Os valores da herdabilidade no sentido amplo $\left(\mathrm{h}_{\mathrm{a}}^{2}\right)$ entre as médias dos genótipos estudados evidenciaram grandes possibilidades de sucesso com a seleção em ordem decrescente para as variáveis diâmetro $(85,42 \%)$, comprimento $(85,34 \%)$ e produtividade de raízes comerciais $(81,55 \%)$. Estes valores de alta magnitude refletem considerável presença do componente genético na expressão destes caracteres. As outras variáveis apresentaram valores de $h_{a}{ }^{2}$ 
baixos, pois, segundo Cavalcante et al. (2009), é necessário o mínimo de 80,0\% para obter ganhos genéticos satisfatórios com a seleção. Adicionalmente, o quociente entre o $\mathrm{CV}_{\mathrm{g}} / \mathrm{CV}_{\mathrm{e}}$ apresentou valores superiores à unidade para o diâmetro $(1,21)$, o comprimento $(1,21)$ e a produtividade comercial $(1,05)$, ratificando que a seleção baseada nessas características poderia ser realizada com eficiência.

De acordo com o dendrograma (Figura 1), constatou-se similaridade entre os clones. Os clones mais semelhantes foram CNPH 02 e Brazlândia Rosada $(1,03)$ e os mais dissimilares foram o clone CNPH 35 e a cultivar Coquinho $(6,72)$. Foi observado um genótipo com morfologia única (CNPH 69) e a formação de dois grupos morfológicos discriminados da seguinte forma: um grupo com dez e sete materiais (CNPH 59, Brazlândia Rosada, CNPH 02, CNPH 1796, CNPH 29, Coquinho, CNPH 87, CNPH 90, CNPH 80, CNPH 41, CNPH 08, CNPH 62, CNPH 71, CNPH 12, CNPH 28, CNPH 55 e CNPH 61) e outro grupo com a cultivar Princesa e os clones CNPH 35, CNPH 46, CNPH 56 e CNPH 60.

Dentro do grupo com 17 materiais, detectou-se certa coincidência entre similaridade genética e origem geográfica dos clones, pois alguns destes, provenientes da mesma localidade, apresentaram distâncias de ligação muito curtas, como é o caso, por exemplo, do clone CNPH 02 e a cultivar Brazlândia Rosada coletados na região de Brazlândia-DF. No entanto, a associação entre origem geográfica e similaridade genética de culturas propagadas assexuadamente, como a batata-doce, não é muito comum, pois os acessos são deslocados entre localidades sem haver intercâmbio de genes, pelo processo sexual, entre materiais exógenos e locais (Oliveira et al., 2000).

A presença de mais de um clone no mesmo grupo (Figura 1) infere a possibilidade de ocorrência de acessos duplicados entre o conjunto de materiais (Oliveira et al., 2000). Portanto, cruzamentos entre estes genótipos provavelmente não seriam efetivos na obtenção de variabilidade genética para os caracteres quantitativos avaliados
(Silva et al., 2012). Já os clones reunidos em grupos mais distantes dão um indicativo de serem dissimilares, podendo ser considerados promissores na escolha de progenitores para cruzamentos artificiais, com grande possibilidade de obter populações segregantes superiores. Contudo, apesar da divergência, os clones escolhidos devem apresentar complementação gênica, associada com média elevada e variabilidade para os caracteres avaliados (Martins et al., 2012).

Silva et al. (2012), avaliando a divergência genética entre 11 acessos de batata-doce utilizando caracteres fenotípicos de raiz, observaram a formação de três agrupamentos, sendo que a maioria dos acessos apresentou níveis elevados de similaridade para as características avaliadas. Já Martins et al. (2012), analisando a variabilidade fenotípica e a divergência genética em 50 clones de batata-doce no estado do Tocantins, identificaram oito grupos geneticamente disjuntos.

Na Tabela 3 é apresentada a matriz de correlação entre as variáveis analisadas e as dimensões da análise de componentes principais. A PCA revelou que os três primeiros componentes principais explicaram 39,50, 27,79 e 13,62\% da variância, acumulando $80,90 \%$ da variabilidade total existente. Isto demonstra que os descritores empregados discriminaram satisfatoriamente os genótipos analisados. Observou-se que, para o primeiro componente principal, os descritores de maior contribuição na discriminação dos genótipos foram o comprimento médio (- 0,73$)$, a espessura do córtex das raízes $(-0,71)$ e o número de furos causados por insetos do solo $(-0,70)$; no segundo componente, destacaram-se a produtividade comercial $(0,77)$ e total das raízes $(0,74)$; no terceiro componente sobressaiu a variável diâmetro $(0,58)$ e no quarto componente o formato das raízes $(-0,74)$ foi a única característica que contribuiu significativamente para a variabilidade dos clones.

Na Figura 2 encontra-se a representação gráfica dos materiais no sistema de eixos, com base nos três primeiros componentes principais. De acordo com a dispersão espacial dos clones no plano multidimensional e com suas caracterís- ticas, foi observada a formação de três grupos, como previamente confirmado pela análise de agrupamento dos clones através de medidas baseadas na distância Euclidiana.

Através do dendrograma e do gráfico dos scores e loadings dos componentes principais 1 e 2 (Figura 2a), é possível verificar que o clone CNPH 69, o qual apresentou morfologia única, encontra-se deslocado em relação aos demais materiais. O primeiro componente principal, que descreveu 39,50\% da variância total dos dados, foi responsável pela separação deste genótipo, que apresentou as maiores produtividades comercial $(47,12 \mathrm{t} / \mathrm{ha})$ e total $(47,54 \mathrm{t} /$ ha) e o maior comprimento de raízes $(38,30 \mathrm{~cm})$ e número de furos causados por insetos de solo $(20,65)$. Já o segundo componente principal (Figura 2a), que descreveu $27,79 \%$ da variabilidade existente, agregou os clones CNPH 56, CNPH 60 e CNPH 46 que exibiram altas produtividades comercializáveis $(24,06$, 36,22 e $29,36 \mathrm{t} / \mathrm{ha}$, respectivamente) e totais $(25,71,36,56$ e 29,36 t/ha, respectivamente) e a cultivar Princesa e o clone CNPH 35, os quais apresentaram elevado número de furos (18,89 e 20,06, respectivamente). De acordo com este componente, o clone CNPH 12, mostrou as piores produtividades.

Através do gráfico dos scores e loadings dos componentes principais 1 e 3 (Figura 2b), visualiza-se que o terceiro componente principal tambem contribuiu para juntar os genótipos CNPH 60 e CNPH 56, devido a seus maiores diâmetros de raízes $(6,55$ e 9,03 $\mathrm{cm}$, respectivamente).

Verificou-se que houve correlação forte entre algumas variáveis como, por exemplo, PC e PT e NF e ID (Figura 2a; $2 \mathrm{~b}$ ), indicando que altas produtividades comercializáveis aumentam a produtividade total das raízes e que, quanto maior o número de furos ocasionados por insetos do solo, maiores as incidências de danos.

Uma estimativa de correlação genotípica positiva e alta entre caracteres demonstra que na prática há necessidade de avaliar apenas o caráter de mais fácil determinação, pois a seleção estará sendo realizada de forma indireta também para o outro, podendo-se inferir, com as 
altas estimativas, que os genes que controlam um caráter podem ser os mesmos que controlam o outro (pleiotropia), ou esses, por sua vez, estão ligados (Gonçalves Neto et al., 2012).

A produtividade comercial e total de raízes frescas incrementou com o aumento do comprimento das raízes, que pela sua vez acarretou em raízes com maiores diâmetros (Figura 2a; 2b). Finalmente, verificou-se correlação positiva entre o diâmetro das raízes e a espessura do córtex, o que indica que raízes com maior espessura de córtex, apresentam maior diâmetro.

Constatou-se que a maioria dos materiais genéticos avaliados é semelhante com relação aos descritores morfoagronômicos das raízes utilizados. Contudo, os cruzamentos entre genitores de grupos diferentes como o clone $\mathrm{CNPH}$ 69, o qual se destacou por suas altas produtividades comercial e total; o clone CNPH 80, que exibiu bom formato e moderada resistência aos insetos de solo e o clone CNPH 60, que apresentou raízes com diâmetro de batata-doce do tipo extra A; podem ser indicados para compor programas de intercruzamentos, visando aumentar as chances de obtenção de variabilidade genética, ganhos com a heterose e genótipos superiores.

\section{AGRADECIMENTOS}

À Coordenação de Aperfeiçoamento de Pessoal de Nível Superior (Capes), pela concessão da bolsa de estudos ao primeiro autor.

\section{REFERÊNCIAS}

ANDRADE JÚNIOR VC; VIANA DJS; PINTO NAVD; RIBEIRO KG; PEREIRA RC; NEIVA IP; AZEVEDO AM; ANDRADE PCR. 2012. Características produtivas e qualitativas de ramas e raízes de batata-doce. Horticultura Brasileira 30: 584-589.

AZEVEDO SM. 1995. Avaliação de famílias de meios-irmãos de batata-doce (Ipomoea batatas) quanto à resistência aos nematóides do gênero Meloidogyne e aos insetos de solo. Lavras: UFLA. 91p (Dissertação mestrado).

AZEVEDO SM; FREITAS JA; MALUF WR; SILVEIRA MA. 2000. Desempenho de clones e métodos de plantio de batata-doce. Acta Scientiarum 22: 901-905.

BARRETO HG; SANTOS LB; OLIVEIRA GIS;
SANTOS GR; FIDELIS RB; SILVEIRA MA; NASCIMENTO IR. 2011. Stability and adaptability in the yield and reaction to soil insects in commercial and experimental genotypes of sweet potato. Bioscience Journal 27: 739-747.

BORGES A; ROSA MS; RECCHIA GH; QUEIROZ-SILVA JR; BRESSAN EA; VEASEY EA. 2009. CTAB methods for DNA extraction of sweetpotato for microsatellite analysis. Scientia Agricola 66: 529-534.

BUZAR AGR; OLIVEIRA VR; BOITEUX, LS. 2007. Estimativa da diversidade genética de germoplasma de cebola via descritores morfológicos, agronômicos e bioquímicos. Horticultura Brasileira 25: 527-532.

CARDOSO AD; VIANA AES; RAMOS PAS; MATSUMOTO SN; AMARAL CLF; SEDIYAMA T; MORAIS OM. 2005. Avaliação de clones de batata-doce em Vitória da Conquista. Horticultura Brasileira 23: 911-914.

CASTRO LAS; TREPTOW RO; CAMPOS AD; CHOER E; THÜRMER L. 2009. Acessos de batata-doce do banco ativo de germoplasma da Embrapa Clima Temperado recomendados para mesa e processamento industrial. Pelotas: Embrapa Clima Temperado. 26p.

CAVALCANTE JT; FERREIRA PV; SOARES L. 2012. Correlações fenotípicas, genotípicas e de ambiente em clones de batata-doce (Ipomoea batatas). Ciência Agrícola 10: 1-7.

CAVALCANTE M; FERREIRA PV; PAIXÃO SL; COSTA JG; PEREIRA RG; MADALENA JAS. 2009. Potenciais produtivo e genético de clones de batata-doce. Acta Scientiarum 31: 421-426.

CIP - Centro Internacional de la Papa. 2013. Facts and figures about sweetpotato. Disponível em: http://cipotato.org/sweetpotato/facts-2/. Acessado em 25 de março de 2013.

CRUZ CD. 2013. GENES - a software package for analysis in experimental statistics and quantitative genetics. Acta Scientiarum 35: 271-276.

DAROS M; AMARAL JÚNIOR AT; PEREIRA TNS; LEAL NR; FREITAS SP; SEDIYAMA T. 2002. Caracterização morfológica de acessos de batata-doce. Horticultura Brasileira 20: 43-47.

ERPEN L; STRECK NA; UHLMANN LO; LANGNER JA; WINCK JEM; GABRIEL LF. 2013. Estimating cardinal temperatures and modeling the vegetative development of sweet potato. Revista Brasileira de Engenharia Agricola e Ambiental 17: 1230-1238.

FABRI EG. 2009. Diversidade genética entre acessos de batata-doce (Ipomoea batatas) avaliada através de marcadores microssatélites e descritores morfoagronômicos. Piracicaba: USP-ESALQ. 172p (Tese doutorado).

FAO - Food and Agriculture Organization of the United Nations. 2012. FAOSTAT, estadísticas de producción de alimentos. Disponível em: http://faostat.fao.org/site/567/DesktopDefault. aspx?PageID=567\#ancor. Acessado em 20 de abril de 2013.

FELTRAN JC; FABRI EG. 2010. Batata-doce: uma cultura versátil, porém sub-utilizada. Nosso Alho 6: 28-31.
FIGUEIREDO JA. 2010. Seleção de clones de batata-doce com potencial de utilização na alimentação humana e animal. Diamantina: UFVJM. 54p (Dissertação mestrado).

FRANÇA FH; MIRANDA JEC; FERREIRA PE; MALUF WR. 1983. Comparação de dois métodos de avaliação de germoplasma de batata-doce visando resistência a pragas do solo. In: CONGRESSO BRASILEIRO DE OLERICULTURA, 23. Anais... Rio de Janeiro: SOB. p.176.

GONÇALVES NETO AC; MALUF WR; GOMES LAA; MACIEL GM; FERREIRA RPD; CARVALHO RC. 2012. Correlação entre caracteres e estimação de parâmetros populacionais para batata-doce. Horticultura Brasileira 30: 713-719.

IBGE - Instituto Brasileiro de Geografia e Estatística. 2012. Produção agrícola municipal: culturas temporárias e permanentes - PAM. Disponível em: http://biblioteca.ibge. gov.br/visualizacao/periodicos/66/pam_2012 v39_br.pdf. Acessado em 01 de janeiro de $201 \overline{4}$.

MARTINS ECA; PELUZIO JM; COIMBRA RR; JUNIOR WPO. 2012. Variabilidade fenotípica e divergência genética em clones de batatadoce no estado do Tocantins. Revista Ciência Agronômica 43: 691-697.

MASSAROTO JA; MALUF WF; GOMES LAA; FRANCO HD; GASPARINO CF. 2014. Desempenho de clones de batata-doce. Ambiência 10: 73-81.

MIRANDA JEC; FRANÇA FH; CARRIJO OA; SOUZA AF; PEREIRA W; LOPES CA; SILVA JBC. 1995. A cultura da batatadoce. Embrapa/Centro Nacional Pesquisa de Hortaliças. 94p.

NEIVA IP; ANDRADE JÚNIOR VC; VIANA DJS; FIGUEIREDO JA; MENDONÇA FILHO CV; PARRELLA RAC; SANTOS JB. 2011. Caracterização morfológica de acessos de batata-doce do banco de germoplasma da UFVJM, Diamantina. Horticultura Brasileira 29: 537-541.

OLIVEIRA ACB; SEDIYAMA MAN; SEDIYAMA T; CRUZ CD. 2000. Avaliação da divergência genética em batata-doce por procedimentos multivariados. Acta Scientiarum 22: 895-900.

PAIXÃO SL; CAVALCANTE M; FERREIRA PV; MADALENA JAS; PEREIRA RG. 2008. Divergência genética e avaliação de populações de milho em diferentes ambientes no estado de Alagoas. Caatinga 21: 191-195.

PEIXOTO JR; SANTOS LC; RODRIGUES FA; JULIATTI FC; LYRA JRM. 1999. Seleção de clones de batata-doce resistentes a insetos de solo. Pesquisa Agropecuária Brasileira 34: 385-389.

PERONI N; MARTINS PS; ANDO A. 1999. Inter- and intraspecific diversity and use of multivariate analysis for the morphology of cassava (Manihot esculenta): a case study. Scientia Agricola 56: 587-595.

QUEIROGA RCF; SANTOS MA; MENEZES MA; VIEIRA CPG; SILVA MC. 2007. Fisiologia e produção de cultivares de batata-doce em função da época de colheita. Horticultura Brasileira 25: 371-374. 
R Core Team. 2013. R: A language and environment for statistical computing. $\mathrm{R}$ Foundation for Statistical Computing, Vienna, Austria. Disponível em: http://www.R-project. org/. Acessado em 26 de dezembro de 2013.

RITSCHEL PS; HUAMÁN Z. 2002. Variabilidade morfológica da coleção de germoplasma de batata-doce da Embrapa - Centro Nacional de Pesquisa de Hortaliças. Pesquisa Agropecuária Brasileira 37: 485-492.

ROESLER PVSO; GOMES SD; MORO E;
KUMMER ACB; CEREDA MP. 2008 Produção e qualidade de raiz tuberosa de cultivares de batata-doce no Oeste do Paraná Acta Scientiarum 30: 117-122.

SILVA JBC; LOPES CA; MAGALHÃES JS. Batata-doce (Ipomoea batatas). 2004. Embrapa Hortaliças. Versão Eletrônica. Sistemas de produção, 6. Disponível em: corhttp://sistemasdeproducao.cnptia.embrapa. br/FontesHTML/Batata-doce/Batata-doce Ipomoea_batatas/introducao.html. Acessado em 08 de novembro de 2014.

SILVA GO; PONIJALEKI R; SUINAGA FA. 2012. Divergência genética entre acessos de batata-doce utilizando caracteres fenotípicos de raiz. Horticultura Brasileira 30: 595-599.

VIANA DJS. 2009. Produção e qualidade de raizes, ramas e silagem de ramas de clones de batata-doce em diferentes locais e épocas de colheita. Diamantina: UFVJM. 69p (Dissertação mestrado). 